\title{
Emergency Nurses' Department Design Recommendations for Improved End-of-Life Care
}

\author{
Renea L. Beckstrand \\ Brigham Young University - Provo \\ Elise M. Corbett \\ Brigham Young University - Provo \\ Janelle L. B. Macintosh \\ Brigham Young University - Provo, janelle-macintosh@byu.edu \\ Karlen E. (Beth) Luthy \\ Brigham Young University - Provo \\ Ryan J. Rasmussen

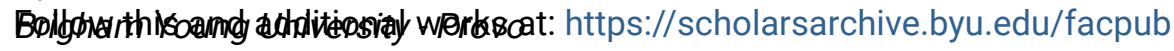 \\ Part of the Critical Care Nursing Commons, and the Other Nursing Commons
}

\section{Original Publication Citation}

Beckstrand, R. L., Corbett, E. M.**, Macintosh, J. L., Luthy, K. E. B., \& Rasmussen, R. J. (2019). Emergency nurses' department design recommendations for improved end-of-life care. Journal of Emergency Nursing, 45(3), 286-294.

\section{BYU ScholarsArchive Citation}

Beckstrand, Renea L.; Corbett, Elise M.; Macintosh, Janelle L. B.; Luthy, Karlen E. (Beth); and Rasmussen, Ryan J., "Emergency Nurses' Department Design Recommendations for Improved End-of-Life Care" (2018). Faculty Publications. 5210.

https://scholarsarchive.byu.edu/facpub/5210

This Peer-Reviewed Article is brought to you for free and open access by BYU ScholarsArchive. It has been accepted for inclusion in Faculty Publications by an authorized administrator of BYU ScholarsArchive. For more information, please contact ellen_amatangelo@byu.edu. 


\section{Emergency Nurses’ Department Design RECOMMENDATIONS FOR IMPROVED END-OF-LIFE CARE}

Authors: Renea L. Beckstrand, PhD, RN, CCRN, CNE, Elise M. Corbett, BSN, Janelle L.B. Macintosh, PhD, RN, Karlen E. (Beth) Luthy, DNP, RN, FNP-c, FAAN, and Ryan J. Rasmussen, PhD(c), RN, FNP-c, Provo, UT

\section{CE Earn Up to 7.5 Hours. See page 341 .}

\section{Contribution to Emergency Nursing Practice}

- The current state of scientific knowledge on emergency nurses' perceptions of the impact of ED designs on end-of-life care for dying patients and their families indicates many obstacles still exist such as limited space, poor department design, and the lack of privacy for patients.

- The main finding of this research is the need for improved areas for family presence during resuscitation, areas for improved body stowage, and the need for more resuscitation rooms.

- Key implications for emergency nursing practice from this research are empowering emergency nurses to become directly involved in ED layout and design modifications specifically to improve space, work flow, and privacy needs at the end of life.

\begin{abstract}
Introduction: Although death is common in emergency departments, there is limited research regarding ED design as an obstacle to end-of-life care. This study identifies emergency nurses' recommendations regarding ways designs have negative or positive impact on care for dying patients and their families.
\end{abstract}

Methods: A 25-item questionnaire was sent to a national random sample of 500 emergency nurses. Inclusion criteria were nurses who could read English, worked in emergency departments, and had cared for at least 1 patient at the end of life (EOL). Responses were individually reviewed and coded.

Results: Major obstacles included (1) issues related to limited space, (2) poor department layout and design, and (3) lack of privacy. Despite emergency departments being a challenging place to provide EOL care, positive ED design characteristics had impact on EOL care.

Discussion: Emergency nurses understand the need for family presence during resuscitation, for secure body stowage areas, and for more resuscitation rooms so that families have time to grieve before being removed because of the immediate needs of a second trauma patient. Nurses can evaluate existing facilities to identify areas in which potential change and remodeling could improve care, increase patient privacy, or further utilize space. Understanding ED design's impact on EOL care is crucial. Modifications to ED layout and design may be challenging; however, improvements to space, layout, and privacy need to be considered when planning new emergency departments or remodeling existing departments. Further research is required to determine the impact of $\mathrm{ED}$ design on EOL care.

Key words: End of life; Emergency department; Design; Emergency nurses; Obstacles
Renea L. Beckstrand is Professor at Brigham Young University, Provo, UT. Elise M. Corbett is Graduate NP Student at Brigham Young University, Provo, UT.

Janelle L.B. Macintosh is Assistant Professor at Brigham Young University, Provo, UT.

Karlen E. (Beth) Luthy is Associate Professor at Brigham Young University, Provo, UT.

Ryan J. Rasmussen is Assistant Teaching Professor, Brigham Young University, Provo, UT.

This project was funded by a grant from Brigham Young University College of Nursing.
For correspondence, write: Renea L. Beckstrand, PhD, RN, CCRN, CNE, Brigham Young University College of Nursing, $422 \mathrm{KMBL}$, Provo, UT 84602; E-mail: renea@byu.edu.

J Emerg Nurs 2019;45:286-94.

Available online 13 July 2018

0099-1767

Copyright (C) 2018 Emergency Nurses Association. Published by Elsevier Inc. All rights reserved.

https://doi.org/10.1016/j.jen.2018.05.014 


\section{Introduction}

Death occurs frequently in emergency departments. In 2013, there were 130.3 million ED visits reported in the United States, as documented in the National Hospital Ambulatory Medical Care Survey. ${ }^{1}$ An estimated 303,000 of those patients were pronounced dead on arrival or died shortly after being admitted to emergency departments. ${ }^{1}$ Large numbers of admitted ED patients dying signifies that death is a common occurrence for emergency nurses.

Although death occurs frequently, emergency nurses face unique obstacles in providing quality end-of-life (EOL) care to dying patients and family members. ${ }^{2-4}$ In addition, obstacles present in emergency departments can make providing EOL care stressful and challenging for emergency nurses. ${ }^{5}$ One previously identified obstacle has been the design or layout of the emergency department. ${ }^{2}$ Therefore, the purpose of this study was to identify emergency nurses' experiences regarding ways ED designs have negative or positive impact on EOL care for dying patients and their families.

\section{Background}

Emergency departments are often the health care entry point where patients present following acute, chronic, or traumatic events. Emergency nurses desiring to provide excellent, compassionate EOL care to dying patients may encounter obstacles at the emergency department. Although much has been published on EOL care obstacles in emergency departments, ${ }^{2-9}$ there is a paucity of research regarding ED design as an obstacle to EOL care. ${ }^{6}$

In 2006, Heaston et $\mathrm{al}^{3}$ completed a national survey of 300 emergency nurses and determined the largest obstacles to providing EOL care were those related to increased patient workload, angry family members, and poor ED design. In a follow-up report, adding frequency-ofoccurrence data, researchers found poor ED design as the obstacle with the second highest magnitude score (mean size multiplied by mean frequency of occurrence). ${ }^{2}$ Of the top 5 most frequent suggestions for reducing EOL care obstacles in the emergency department, 3 focused on environment or design including providing comfortable patient rooms, more privacy at the EOL, and places for families to grieve. ${ }^{8}$

In a study on rural emergency nurse perceptions of EOL care $(\mathrm{n}=508)$, Beckstrand et $\mathrm{al}^{9}$ found the third highest obstacle was poor ED design that did not allow for privacy of dying patients or grieving family members In a more recent analysis of qualitative data gathered during the original study, ${ }^{7}$ Beckstrand et $\mathrm{al}^{7}$ found the most frequent suggestion for improving EOL care in rural emergency departments was providing greater privacy. These rural emergency nurses overwhelmingly identified privacy as the top priority when providing EOL care in rural emergency departments. ${ }^{7}$ Subsequent studies have evaluated obstacles to EOL care in the emergency department and also identified poor department design as a significant barrier to quality EOL care, primarily due to poor or limited space in emergency departments and the lack of privacy. ${ }^{4,5}$

In a landmark study investigating emergency nurses' perceptions of department design as an EOL care obstacle, researchers found $\mathrm{ED}$ design might not be as large an obstacle as previous studies suggested. ${ }^{6}$ A 25 -item questionnaire was mailed to a national random sample of $500 \mathrm{mem}$ bers of the Emergency Nurses Association (ENA). Two mailings of the questionnaire elicited 198 usable responses for a response rate of $40.9 \%$. Emergency nurses reported that their current ED design helped EOL care at a greater rate than current design obstructed care. Emergency nurses also reported having little input into unit design or layout changes. The primary request by emergency nurses for ED design changes was for more private places for families to grieve. ${ }^{6}$

\section{RESEARCH QUESTIONS}

Research on EOL care obstacles as perceived by emergency nurses in the emergency department has been published; $;^{2-9}$ however, there is a lack of studies concerning ED design as an obstacle to EOL care. No studies were found that focused specifically on ED nurses' recommendations for improved ED design. This study builds on previously published quantitative research looking at ED design.

The research questions were as follows: (1) What are the shared experiences regarding ED design that epitomize obstacles to providing EOL care? (2) What aspects of ED design do emergency nurses identify as obstacles to EOL care? (3) What positive aspects of ED design do emergency nurses identify as promoting quality EOL care for dying patients and their families?

Emergency nurses' perceptions of design obstacles are important. Understanding emergency nurses' perceptions of design obstacles is needed as a means to develop better department designs that enhance provision of EOL care. 


\section{Methods}

\section{SUBJECTS}

After Institutional Review Board (IRB) approval, a national random sample of 500 emergency nurse participants was purchased from ENA. Participants were eligible for inclusion if nurses had worked in emergency departments, lived in the United States, were able to read English, and had cared for at least 1 dying patient. Consent to participate was implied upon return of the questionnaire.

\section{INSTRUMENT}

The 'Emergency Nurses' Perceptions of Department Design as an Obstacle to End-of-Life Care" questionnaire was created using information gathered from literature review, previously completed research, ${ }^{2,3,8,9}$ and expert opinion. The questionnaire included 6 quantitative, 3 qualitative, and 16 demographic items for a total of 25 . Quantitative data from this research study have been previously published. ${ }^{6}$ The open-ended question analyzed for this study was "Can you tell us of any experiences in which the ED design had either a negative or positive impact on the EOL care you provided to your dying patients or their family members?"

\section{PROCEDURE}

A geographically dispersed, national random sample of members of ENA was purchased. The first mailing included a cover letter explaining the study, a copy of the questionnaire, a $\$ 1$ bill as compensation, and a self-addressed stamped return envelope. A second mailing was completed 6 to 8 weeks after the initial mailing to all nonresponders. The second mailing included a cover letter, a copy of the questionnaire, and a self-addressed stamped return envelope.

\section{DATA ANALYSIS}

Data were returned and entered into a Microsoft Word (2013) file for analysis (Microsoft Corporation, Redmond, Washington). The research team included an EOL care nurse researcher with more than 25 years of research experience, 2 advanced practice nurse practitioners (NPs), a $\mathrm{PhD}$-prepared qualitative research expert, and a graduate FNP student who works as an emergency nurse. Content analysis was used to identify categories and themes of the qualitative responses. Members of the research team analyzed data to identify preliminary themes, then analysis continued as a team to finalize the results and achieve consensus.

\section{Results}

Of the 500 mailed questionnaires, 215 were returned. Of the 215 returned questionnaires, 17 were eliminated from the study sample because questionnaires were undeliverable $(\mathrm{n}=16)$ or because a subject self-reported as ineligible to participate $(n=1)$. Thus, the final sample size was 198 emergency nurses. Of those nurses, 126 provided usable responses to the open-ended question for a response rate, on this item, of $63.6 \%$. Many nurses provided more than 1 , making the total number of recommendations 158 .

Of the subjects who responded to gender, 24 (19\%) were male and $102(81 \%)$ were female. The mean age of nurses was 47.4 years (standard deviation $[\mathrm{SD}]=10.0$ ), with a range of 26 to 68 years. Nurses reported a mean of 19.4 years $(\mathrm{SD}=11.9)$ working as a $\mathrm{RN}$ and a mean of 14.6 years $(\mathrm{SD}=10.5)$ of total ED experience. Greater than $61 \%$ of these nurses reported having provided care for 30 or more ED patients at EOL (Table 1).

\section{SHARED EXPERIENCES REGARDING DESIGN OBSTACLES}

Several themes emerged from emergency nurses' experiences. Nurses identified the emergency department as a challenging place to provide EOL care owing to many obstacles. Major obstacles relating to ED design included (1) many issues related to limited space, (2) poor department layout and design features, and (3) the lack of privacy (Table 2).

The most commonly identified ED obstacle $(\mathrm{n}=50$; $31.6 \%)$ was limited space and the many problems that comprised this obstacle. Although small rooms and lack of storage were general design obstacles, specific issues with limited space included no place for family members at patients' bedsides, during resuscitation, or for deceased body stowage after death.

Overall, emergency nurses determined that limited space was not conducive to appropriate EOL care for dying patients and families. One nurse voiced the concerns of many by sharing this example of limited space, "[Trauma] care rooms are too small with all the equipment needed and we lack additional storage places." Other specific comments related to inadequate space for family members during resuscitation or for body stowage after death. 
TABLE 1

Demographics of nurses $n=126$

\section{Characteristics}

\section{Sex, n (\%)}

Male

Female

$102(81)$

Age (y)*

47.4; $10.0(26-68)$

Years as $\mathrm{RN}^{*}$

$19.4 ; 11.9(1-47)$

Years in emergency department*

Hours worked/week*

ED beds in unit*

Years as $\mathrm{CEN}^{*}$

Dying patients cared for, $\mathrm{n}(\%)$

$\begin{array}{lll}>30 & 75 & (61.5) \\ 21-30 & 9 & (7.4) \\ 11-20 & 14 & (11.5) \\ 5-10 & 16 & (13.1) \\ <5 & 8 & (6.6)\end{array}$

Highest degree, n (\%)

Diploma 5

Associate 29

Bachelor $\quad 62$

Master 26

Ever certified as CEN, n (\%)

Yes

No

Currently CEN, n (\%)

Yes

No

Primary position, n (\%)

Direct care/bedside nurse $\quad 44$

Staff/charge nurse $\quad 44$

Nurse manager $\quad 15$

Nurse Educator 3

Clinical nurse specialist $\quad 1$

Other

Hospital type, n (\%)

Adult/Pediatrics 108

Adults Only

Pediatrics Only

\section{9}

5

Facility type, n (\%)

Community, nonprofit $\quad 74$

Community, profit 22

University Medical Center 14
TABLE 1

Continued

\begin{tabular}{lll}
\hline Characteristics & & \\
\hline County hospital & 5 & $(4.1)$ \\
Military hospital & 2 & $(1.6)$ \\
Other & 5 & $(4.1)$
\end{tabular}

$M$, mean; $S D$, standard deviation. ${ }^{*}$ Data presented as M; SD (range).

\section{Space For Family Members}

Emergency nurses noted that inadequately sized rooms limited family members at the bedside of the dying patient. One nurse stated, "Rooms are too crowded for dying patients and their families." Another nurse responded, "There is nowhere for family members to fit in rooms so families consistently need to be in the hallway." One nurse described the obstacle of limited space in the emergency department through the following comment:

"There is rarely space for families of the deceased to be [present] after the death of their loved one. Emergency departments do not allow space for this aspect of care. We have a small family room and chapel, but it is less than ideal for the needs of families."

\section{Space During Resuscitation}

Family members are often encouraged to be present during resuscitation efforts; however, limited space often can make family presence difficult for ED staff. One nurse shared the following:

"During the code of a young child in our major trauma room, there was no room for multiple family members to observe the code. The only [space] was in the hallway in the middle of the emergency department in view of other patients and visitors".

Another emergency nurse further articulated the obstacle of limited space during resuscitation by saying, "Some rooms in the department are too small to have a code [while] the family is present without tripping over staff." Another nurse stated, "We seldom have family members present for resuscitation mainly because we do not have adequate space in the patient-care area."

\section{Deceased Body Stowage}

Limited space in the ED also affected where emergency nurses placed patients' bodies after death. Several nurses reported that there are frequently no holding places for 


\section{TABLE 2}

\section{Design obstacles and positive design elements

1. Issues surrounding limited space and lack of storage $(n=50 ; 31.6 \%)$ a. Limited space for family members

b. Limited space during resuscitation

c. Limited deceased body stowage

2. Poor department layout and design features $(n=43 ; 27.2 \%)$
a. Curtains as separators
b. Lack of family grieving rooms
c. Department layout issues
d. Shortage of resuscitation rooms
3. Lack of privacy $(\mathrm{n}=33 ; 20.9 \%)$

\section{Large private rooms}

2. Family grieving rooms

3. Rooms with close proximity to nurses' stations deceased bodies in emergency departments. One nurse noted,

"During the busy flu season, we frequently have to add rooms to our rooms (i.e. hallway beds or two beds to a room). I have had to put a deceased patient's body off to the side, behind curtains, or in x-ray room because we do not have an appropriate place."

Another nurse shared an unacceptable experience regarding inappropriate placement of deceased bodies due to lack of room on an extraordinarily busy day.

"We had two trauma rooms for [more than] 140 patients a day. One night we received 5 codes, one after another. Two codes were unsuccessful, and we had to put the bodies somewhere so we could receive the next 2 codes. One body was placed in an elevator that opened into the emergency department. It was blocked off at the time [and normally locked] but, unfortunately, someone unlocked it and when the family arrived the body was going up and down the elevator shaft. The second body was a baby, and because we had no area available the [wrapped] body was placed on a counter top when the third code came in [and the nurse was needed immediately]. At some point the body [mistakenly] got moved to the trash bin and was hard to find."

\section{Department Features and Layout}

Second to lack of space, emergency nurses identified department features and issues related to layout as the second most common obstacle $(\mathrm{n}=43 ; 27.2 \%)$ to EOL care. Many nurses reported that negative design features such as curtain dividers in rooms, the lack of family grieving rooms, generally poor ED room layouts, and insufficient numbers of resuscitation rooms created a challenging environment to provide quality EOL care.

\section{Curtains as Separators}

Many emergency departments use curtains to separate patients and provide a semblance of privacy. Several nurses echoed one nurse's comment: "I see the curtains as a big negative in those rooms no matter how we use them. Just because you can't see what's going on doesn't mean you can't hear." One nurse shared an EOL experience affected by curtains used as patient separators.

"There was a cardiac arrest and the patient was pronounced dead soon after arriving. There were only curtains separating the other patients in the bay. There was not enough room for family. The other patients in the bay (in other curtained off areas) were very aware of what was happening. They were able to hear [the grieving family] through the curtains."

Another nurse described the difficulty of providing EOL care with curtained rooms.

"We had a dying patient in one room trying to pass in peace with his family. Not too far away, separated by only a curtain, a loud intoxicated family was with their daughter cursing, laughing, being loud, foul, and upsetting to the entire emergency department...not allowing the dying patient or family any peace."

\section{Lack of Family Grieving Rooms}

Several nurses reported that it was necessary for family members to stay in waiting rooms or hallways because there was no private area for families. Many emergency departments do not have family grieving rooms or a specified place for 
family members to grieve. One nurse stated, "I worked at an emergency department that did not have a grief room. Patients' family members would have to wait in the main lobby. It was a very bad situation." Another nurse shared an experience of having a dying patient's family members in the waiting room rather than having room for them to be at the bedside:

"[The problem is] limited space in ED rooms and congested halls. [One patient's] family was in the waiting room with other ED patients. Family members got mixed up and the physician informed the wrong family members of [a patient's] death."

\section{Department Layout}

Poor department layout or design, location of rooms in the emergency department, and the proximity of dying patients to the nurses' station make EOL care challenging. One nurse described the obstacle of rooms located in busy areas or near the nurses' station.

"The trauma rooms are right in front of the nurses' station. Family members are mourning in view of everyone. At the same time, everyone at the nurses' station is expected to talk in soft voices, not laugh, and no joking around with each other [during this traumatic time for family]. An ED with a code/trauma room that had more privacy would help the family, staff, and other patients."

Another nurse agreed with the obstacle of room location: "Rooms near the nurses' station where conversations are loud or involve laughing make [staff members] appear insensitive."

\section{Shortage of Resuscitation Rooms}

Owing to the busy nature of emergency departments, resuscitation rooms are often occupied, or there may not be sufficient resuscitation rooms for dying patients and their accompanying family members. One nurse reported, "The shortage of resuscitation rooms often limits the amount of time families can spend with the patient after death." Similarly, another nurse stated, "We normally put EOL patients in our trauma rooms. Then we have to move them out quickly to get ready for the next emergency. We have to move the family; it is loud and very impersonal."

\section{Lack of Privacy}

The lack of privacy was specifically reported by emergency nurses $(\mathrm{n}=33 ; 20.9 \%)$ as a top obstacle to providing EOL care. ED design does not generally facilitate privacy for dying patients and accompanying family members One nurse shared, "Because of the close proximity to any location in our emergency department, there is precious little privacy. Everyone can know what's happening." Similarly, another nurse stated, "In the case of our facility, the treatment rooms are small and 'open concept,' which leaves very little opportunity for privacy from other patients." Another nurse made a comment on the lack of privacy in the emergency department, "Because of the design of the emergency department, other patients know exactly what is going on."

Dying patients are frequently placed in resuscitation rooms; however, these rooms are often in busy areas of the department limiting privacy for patients and family. One nurse stated, "Resuscitation rooms open out into the busy hallways; there is no privacy." Another nurse reported, "The [resuscitation room] is in an area with heavy traffic, it is a large open room, and there is little privacy."

Several nurses noted that the combination of limited space and poor department layout and features create a difficult environment for privacy in the emergency department. One nurse shared an EOL experience in the ED:

"[A] 52-year-old female cancer patient had both DNR and DNI orders but was not expecting to die soon. It was a very busy night. No private areas, actually no room at all to move to in the emergency department. When she died, it was loud and busy with many psych patients along with our usual intoxicated patients screaming at us. Family was very disturbed."

Despite noting many negatives related to ED design, some nurses commented on positive ED design elements that supported and facilitated EOL care.

\section{Positive Design Elements}

Despite emergency departments being a challenging place to provide EOL care, positive ED design characteristics impacted EOL care for dying patients and families. Several nurses $(\mathrm{n}=32,20.3 \%)$ identified positive ED design elements. Supportive design features enhancing EOL care included private rooms with actual doors rather than curtains, large patient rooms for families to gather or to be present during resuscitation, private grieving rooms for families, and patient rooms close to the nurses' station (Table 2).

Large private rooms with doors were overwhelmingly viewed by nurses as an important supportive design element. One nurse stated, "We moved our dying patients 
from rooms with curtains to rooms with doors." Another nurse said, "We have several large private rooms that allow for comfortable EOL care if needed." One nurse shared, "Our emergency department has private rooms without the need to double up patients. This allows for private grieving as well as a consultation room for other family members. [The private room] has positively helped the EOL care."

Also, nurses reported that having designated family grieving rooms helped facilitate EOL care for accompanying family members. One nurse stated, "We have a private consultation room attached to the waiting room and we place families there during resuscitations. I believe [the private grieving room] positively impacts our EOL care, allowing privacy for doctor consults and grieving." Another nurse reported, "Our emergency department has a grieving room with a viewing room attached. The viewing room is optional for family and friends."

Although many nurses believed that rooms near the nurses' station were obstacles to EOL care, several nurses found rooms close to the nurses' station helpful. One nurse stated, "Rooms close to nurses' station allowed for easy monitoring of patients." Similarly, another nurse reported,

"The patient rooms are centered around the nurses' station, so when family members need something we were available to [help] them. It was true for all the nurses on shift and not just the nurse caring for the patient, providing a more comforting and caring environment for the family."

\section{Summary}

Several aspects of ED design were identified by this study as obstacles to EOL care. Themes of limited space, poor department layout and design features, and the lack of privacy were frequently acknowledged by nurses as obstacles to EOL care. In addition, design features that improved EOL care included private rooms with doors, large patient rooms for families to gather or to be present during resuscitation, large private grieving rooms for families, and patient rooms close to the nurses' station.

\section{Discussion}

Many patients die or are pronounced dead in emergency departments. ${ }^{1}$ For more than a decade, emergency nurses have reported design issues as obstacles to EOL care; ${ }^{2-9}$ however, 1 quantitative study specifically addressing EOL care design obstacles failed to confirm previous emergency nurses' opinions regarding severity of impact. ${ }^{6}$ Close examination of the qualitative data presented in this report again confirms emergency nurses' consistent declaration of design/environmental issues as obstacles to EOL care leading researchers to question whether the previous method ${ }^{6}$ to determine severity of impact was flawed. Further research specifically addressing design issue's impact on EOL care is needed.

\section{SHARED EXPERIENCES}

Emergency nurses understand the need for family presence during resuscitation, for secure body stowage areas, and for more resuscitation rooms so that families have time to grieve before being removed due to the immediate need for a second trauma patient and family. Privacy issues related to secure and sound-limiting space were also identified as needs.

Limited space in emergency departments is an obstacle to EOL care. Small rooms and limited space can have negative impact on nurses' ability to provide resuscitation with family members present as well as having areas for body stowage if efforts are unsuccessful. However, the ENA has repeatedly encouraged family presence during resuscitation and EOL care. ${ }^{10}$ Emergency departments, when possible, should allocate appropriate space in patient rooms to allow family presence for dying patients. Furthermore, emergency departments need to plan for secure, accessible locations to place deceased bodies until transported to morgues or mortuaries.

Limited resuscitation rooms decrease allotted time family members spend with dying or deceased patients. Our nurses reported the necessity to hurry and move deceased patients to make room for the next emergency. Similarly, Hogan et $\mathrm{al}^{5}{ }^{5}$ interviewed 11 Canadian emergency nurses and discovered that nurses felt pressured to move on quickly, caring for the next critical patient after a previous patient died. In another study, Bailey et $\mathrm{al}^{11}$ reported that nurses felt a sense of urgency to move dying or deceased patients to provide rooms for other patients. Adding resuscitation rooms to existing emergency departments is difficult; however, nurses need to insist on having input for any future remodeling or planned new construction. Keeping a $\log$ of EOL obstacle incidences could bolster the need for additional rooms and space when changes are announced.

Providing privacy for dying ED patients and family can be difficult. Lack of privacy, as a theme, was consistent with previously published data on EOL care obstacles. ${ }^{2-9}$ In addition, Barlas et $\mathrm{al}^{12}$ found that patients perceive less privacy in rooms with curtains than in rooms with walls 
and doors. According to the Annals of Emergency Medicine, in a policy statement regarding ED planning, patients have a right to "visual and auditory privacy." 13 Patient privacy must be an essential consideration for optimal ED design. When no other option is available, as much space as possible should be provided as a buffer between dying patients and less critical patients and families. The possibility of adding appropriate overhead background music may also help limit noise transfer from one area to another in an open room/bay.

Availability of large private rooms, family grieving rooms, and rooms closer to the nurses' central area were all reported as having positive impact on EOL care. Results from our previous research support these findings. ${ }^{6}$ Having private family grieving areas, more private patient rooms, more space for family presence and observation, and a chapel close to the emergency department were all listed as optimal design changes.

\section{Limitations}

Although the study was a national random sample, responses were limited to members of ENA and can only be generalized to emergency nurses who are members of ENA. Emergency nurses who are not members of ENA may have reported different EOL care obstacles or supportive measures to ED design. Also, with the overall response rate of $63.6 \%$, nonresponders may have expressed different perceptions of design obstacles.

\section{Implications for Emergency Nurses}

Emergency nurses can evaluate existing facilities and identify areas in which potential change and remodeling would improve patient care, increase patient privacy, or further utilize space. To enhance effectiveness, changes in department design need to be reviewed and approved by nurses working in that department. Thus, hospital administrators should view emergency nurses as a resource when planning remodels or designing new departments.

New hospital design teams need to consider aspects of design and layout that influence EOL care in the emergency department. According to several studies on designing new emergency departments, design teams that included staff emergency nurses were beneficial for building new departments that focus on patient-centered care. ${ }^{14-16}$ Emergency nurses need to be on new hospital planning committees to design emergency departments that facilitate quality EOL care. Implementing changes based on emergency nurses' recommendations will improve EOL care for dying ED patients.

\section{Conclusion}

Caring for dying patients is a difficult aspect of emergency nursing. Understanding ED design's impact on EOL care is crucial. ED design can influence a nurse's ability to provide EOL care. There is a need to consider restructuring emergency departments to provide sufficient space for patients and family. Modifications to ED layout and design may be challenging; however, improvements to space, layout, and privacy need to be considered when planning new emergency departments or remodeling existing departments. To provide optimal care to dying patients, further research is required to determine the impact of $\mathrm{ED}$ design on EOL care.

\section{REFERENCES}

1. Center for Disease Control and Prevention. National hospital ambulatory medical care survey: 2013 emergency department summary tables. https://www.cdc.gov/nchs/data/ahcd/nhamcs_emergency/2013_ed_web_ tables.pdf. Accessed January 30, 2017.

2. Beckstrand RL, Smith MD, Heaston S, Bond AE. Emergency nursessesulatory medical care survey: 2013 emergency department summary tables. https://www.cdc.gov/nchs/data/ah J Emerg Nurs. 2008;34(4):290300 .

3. Heaston S, Beckstrand RL, Bond AE, Palmer SP. Emergency nursesseslatory medical care survey: 2013 emergency department summary tables. $J$ Emerg Nurs. 2006;32(6):477-485.

4. Wolf LA, Delao AM, Perhats C, et al. Exploring the management of death: emergency nursessesd supportive challenges and facilitators in the provision of end-of-life care in the emergency department. $J$ Emerg Nurs. 2015;41(5):e23-e33.

5. Hogan K-A, Fothergill-Bourbonnais F, Brajtman S, Phillips S, Wilson KG. When someone dies in the emergency department: perspectives of emergency nurses. J Emerg Nurs. 2016;42(3):207-212.

6. Beckstrand RL, Rasmussen RJ, Luthy KE, Heaston S. Emergency nurses perception of department design as an obstacle to providing end-of-life care. J Emerg Nurs. 2012;38(5):e27-e32.

7. Beckstrand RL, Smith KE, Luthy KE, Macintosh JLB. Rural emergency nurses' suggestions for improving end-of-life care. J Emerg Nurs. 2017;43(3):214-220.

8. Beckstrand RL, Wood RD, Callister LC, Luthy KE, Heaston S. Emergency nursessesomeone dies in the emergency department: perspecg en J Emerg Nurs. 2012;38(5):e7-e14.

9. Beckstrand RL, Giles VC, Luthy KE, Callister LC, Heaston S. The last frontier: rural emergency nursessescy department: perspecg end-of-life care. J Emerg Nurs. 2012;38(5):e15-e25. 
10. Emergency Nurses Association. Emergency nurses association position statement: pallative and end-of-life care in the emergency department. https://www.ena.org/SiteCollectionDocuments/Position\%20Statements/ PalliativeEndOfLifeCare.pdf. Published 2013.

11. Bailey CJ, Murphy R, Porock D. Dying cases in emergency places: caring for the dying in emergency departments. Soc Sci Med. 2011;73(9):1371-1377.

12. Barlas D, Sama AE, Ward MF, Lesser ML. Comparison of the auditory and visual privacy of emergency department treatment areas with curtains versus those with solid walls. Ann Emerg Med. 2001;38(2):135-139.
13. Emergency department Planning and Resource guidelines. Ann Emerg Med. 2014;64(5):564-572.

14. Finefrock SC. Designing and building a new emergency department: the experience of one chest pain, stroke, and trauma center in Columbus, Ohio. J Emerg Nurs. 2006;32(2):144-148.

15. Woitas M, Potthoff S, Nelson E, Matticks C. Innovative ED design for patient-centered care. J Emerg Nurs. 2014;40(5):e105-e110.

16. Forsythe L. Planning a new emergency department: one Pacific Northwest hospital's experience. J Emerg Nurs. 2003;29(4): 330-334 